\section{Terminal differentiation of myelin-forming oligodendrocytes depends on the transcription factor Sox10}

\author{
C. Claus Stolt, ${ }^{1}$ Stephan Rehberg, ${ }^{1}$ Marius Ader, ${ }^{2}$ \\ Petra Lommes, ${ }^{1}$ Dieter Riethmacher, ${ }^{2}$ \\ Melitta Schachner, ${ }^{2}$ Udo Bartsch, ${ }^{2}$ and \\ Michael Wegner ${ }^{1,3}$
}

${ }^{1}$ Institut für Biochemie, Universität Erlangen-Nürnberg, 91054 Erlangen, Germany; ${ }^{2}$ Zentrum für Molekulare Neurobiologie, Universität Hamburg, 20251 Hamburg, Germany

Sox10 is a high-mobility-group transcriptional regulator in early neural crest. Without Sox10, no glia develop throughout the peripheral nervous system. Here we show that Sox10 is restricted in the central nervous system to myelin-forming oligodendroglia. In Sox10-deficient mice progenitors develop, but terminal differentiation is disrupted. No myelin was generated upon transplantation of Sox10-deficient neural stem cells into wild-type hosts showing the permanent, cell-autonomous nature of the defect. Sox10 directly regulates myelin gene expression in oligodendrocytes, but does not control erbB3 expression as in peripheral glia. Sox10 thus functions in peripheral and central glia at different stages and through different mechanisms.

Received September 5, 2001; revised version accepted November 20, 2001.

The strong expression of Sox10 in regions of the central nervous system (CNS) such as corpus callosum and cerebral and cerebellar white matter suggested predominant occurrence in glia (Kuhlbrodt et al. 1998b). To determine the cell type expressing Sox10, we used a Sox $10^{\text {lac } Z}$ knock-in allele that faithfully reproduces Sox 10 expression in the mouse as $\beta$-galactosidase expression (Britsch et al. 2001). X-Gal staining on sections of adult Sox $10^{1 a c Z} /+$ mouse brain revealed that Sox10-expressing cells in the corpus callosum and in the cerebellar white matter had the morphology and formed the linear pearls-on-a-string arrays characteristic of oligodendrocytes (Fig. 1a; data not shown). Oligodendrocyteand myelin-free regions such as the molecular layer of the cerebellar cortex were not stained (data not shown). Sox10 was also expressed in the adult optic nerve, which contains astrocytes and oligodendrocytes but lacks nerve cells. The optic nerve revealed an intense X-gal staining with exception of its most retinal end, which is rich in astrocytes and free of oligodendrocytes. Lack of $\beta$-galactosidase-positive cells in this region is therefore indica-

[Key Words: Sox; glial cells; HMG; PLP; MBP; neuregulin] ${ }^{3}$ Corresponding author.

E-MAIL m.wegner@biochem.uni-erlangen.de; FAX 49-9131-85-22484. Article and publication are at http://www.genesdev.org/cgi/doi/10.1101/ $\operatorname{gad} .215802$. tive of selective Sox10 expression in oligodendrocytes (Fig. 1b). Double immunolabelings in various brain regions furthermore did not reveal a significant overlap between the $\beta$-galactosidase-expressing cell population and cells positive for the pan-neuronal marker NeuN (Fig. 1c) or the astrocytic marker glial fibrillary acidic protein (GFAP; Fig. 1d). Amounts of $\beta$-galactosidase were highest in the somata of expressing cells. Lower levels in the pertaining cellular processes colocalized with the oligodendrocytic markers O4, myelin-associated glycoprotein (MAG), proteolipid protein (PLP), myelin basic protein (MBP) or CNPase (Fig. 1e,f; data not shown). This predominantly oligodendrocytic expression in the CNS contrasts with the pan-glial expression of Sox10 in the peripheral nervous system (PNS).

Sox10 expression in the oligodendrocyte lineage is not restricted to the differentiated cell (Kuhlbrodt et al. 1998b; Zhou et al. 2000). In Sox10 Iacz $/+$ embryos, $\beta$-galactosidase-positive cells were detected at 11.5 days postcoitum (dpc) in a focal region in the ventral part of the ventricular zone of the developing spinal cord, and approximately a day and a half later in the telencephalon at the boundary between hypothalamus and ganglionic eminence (data not shown). At these times, both regions are known to give rise to oligodendrocyte progenitors (for review, see Woodruff et al. 2001). Here we focus on the spinal cord.

At $12.5 \mathrm{dpc}$, the number of Sox10-positive cells in the ventral part of the ventricular zone had increased, and some cells had started to emigrate from this region (Fig. 2a). Through $14.5 \mathrm{dpc}$ and $16.5 \mathrm{dpc}$, some Sox10-positive cells remained in the ventricular zone, the majority dispersed throughout the gray matter (Fig. 2b,c). This pattern is characteristic of oligodendrocyte precursors as evident from comparative in situ hybridizations on adjacent sections with known markers for oligodendrocyte precursors, such as olig2 (Fig. 2i-k) and PDGF receptor $\alpha$ (Fig. 2q,r). In agreement with previous studies (Woodruff et al. 2001), expression of olig2 and Sox10 precedes PDGF receptor $\alpha$. Once expressed, PDGF receptor $\alpha$ labels the same cells as Sox10/ $\beta$-galactosidase, as evident from double immunohistochemistry (Fig. $2 \mathrm{w}-\mathrm{y}$ ). By 18.5 $\mathrm{dpc}$, Sox10-positive cells began to accumulate in the prospective white matter (Fig. 2d), where they start to terminally differentiate and simultaneously lose PDGF receptor $\alpha$ expression (Fig. 2s). Olig2 is still expressed in these cells (Fig. 21).

Using age-matched $\operatorname{Sox} 10^{1 a c z} / \operatorname{Sox} 10^{1 a c z}$ embryos, we analyzed development of oligodendrocyte progenitors in the absence of Sox10. Comparison of the expression patterns of $\beta$-galactosidase (Fig. 2e-h), olig2 (Fig. $2 \mathrm{~m}-\mathrm{p}$ ), and PDGF receptor $\alpha$ (Fig. 2t-v) failed to reveal significant differences in the appearance, distribution, or number of oligodendrocyte progenitors in homozygous Sox10-deficient embryos at any time of embryonic development. As judged from the intensity of the in situ hybridization signal, there was a reduction in the expression levels for PDGF receptor $\alpha$, indicating that its expression is influenced by Sox10. In any case, levels of PDGF receptor $\alpha$ were sufficient to guarantee progenitor generation and survival. This result differs dramatically from the situation in the PNS of Sox $10^{\text {lacz }} /$ Sox $10^{\text {lacZ }}$ embryos, where glial progenitors are already absent (Britsch et al. 2001). 

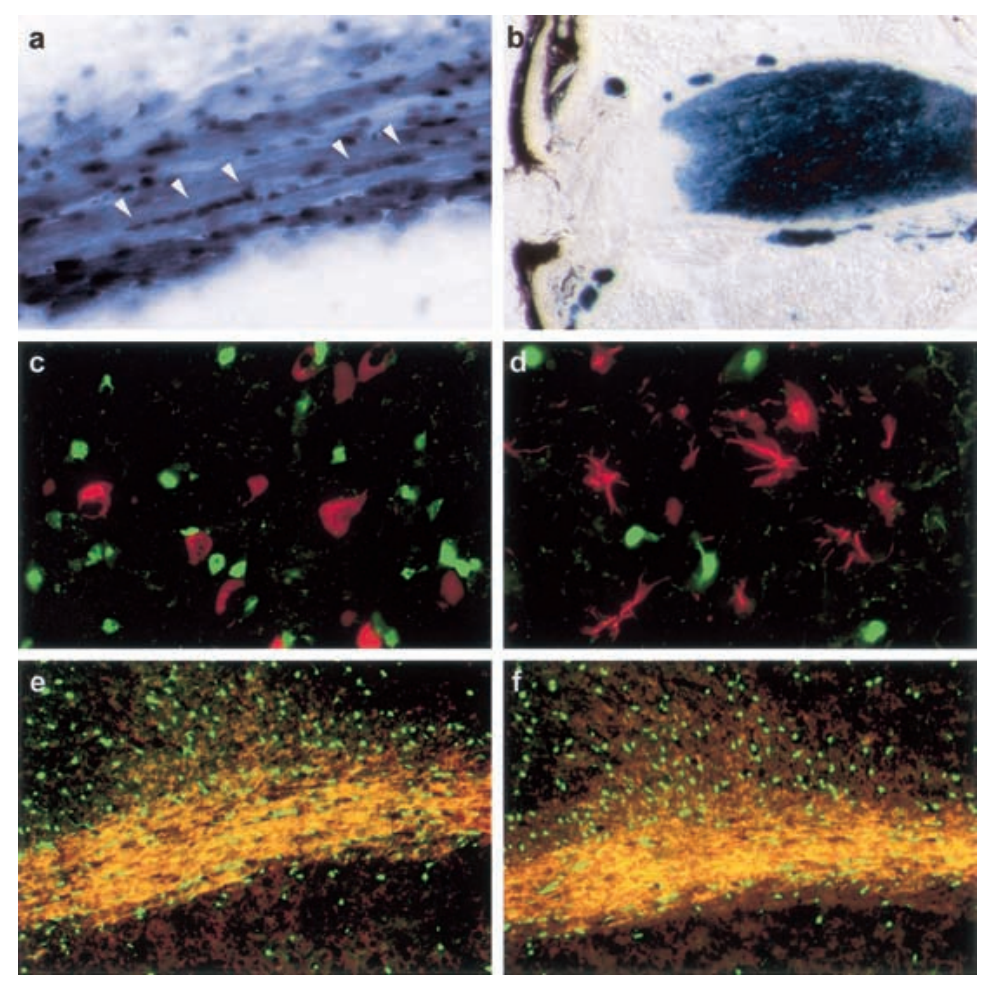

Figure 1. Sox10 expression in the adult CNS. (a) X-Gal-stained section from corpus callosum of an adult Sox $10^{1 a c Z} /+$ mouse. Linear arrays of stained oligodendrocytes are marked by arrowheads. (b) Longitudinal section of X-gal-stained optic nerve from an adult $\operatorname{Sox} 10^{1 a c Z} /+$ mouse. $(c-f)$ Immunohistological analysis of adult brain from Sox $10^{1 a c Z} /+$ mice using antibodies against $\beta$-galactosidase (green) in combination with various celltype-specific antibodies (red), including $\operatorname{NeuN}(c), \operatorname{GFAP}(d), \operatorname{MBP}(e)$, and MAG $(f)$. Pictures were taken at the following magnifications: $40 \times(b) ; 100 \times$ $(e, f) ; 200 \times(a) ; 400 \times(c, d)$.

In late embryogenesis, oligodendrocyte precursors in the presumptive white matter of the spinal cord begin to terminally differentiate and to express myelin genes such as $M B P, P L P$, and MAG. Although these cells are still few at $16.5 \mathrm{dpc}$ in wild-type mice, their number rises dramatically through $18.5 \mathrm{dpc}$ until the day of birth (Fig. 3b-d for MBP; Fig. 3j-1 for PLP; Fig. 3k, inset for MAG). In age-matched Sox $10^{\text {lacZ }} /$ Sox $10^{\text {lac }}$ embryos, there are no PLP-, MAG-, or MBP-positive cells at $16.5 \mathrm{dpc}$ and at $18.5 \mathrm{dpc}$; even on sections of newborn homozygous mice after $20 \mathrm{~d}$ gestation, we detected $<5 \%$ of the MBP- or PLP-positive cells found in wild-type littermates (Fig. 3f-h for MBP; Fig. 3n-p for PLP; Fig. 3o, inset for MAG). This decrease does not appear to be due to apoptosis, because we failed to detect an increase of TUNEL-labeled cells in the oligodendrocyte lineage at $18.5 \mathrm{dpc}$ (data not shown). In the CNS, Sox10 is one of the few transcription factors restricted to the oligodendrocyte lineage (Lu et al. 2000; Xu et al. 2000; Zhou et al. 2000). Coexpression with other Sox proteins (Kuhlbrodt et al. 1998a) or dispensability of its target gene products during early oligodendrocyte development may explain why its role becomes apparent only at the onset of terminal differentiation.

Homozygous Sox10-deficient mice die either before or at birth (Britsch et al. 2001), making it impossible to study the postnatal peak of terminal oligodendrocyte dif- ferentiation and myelination. To circumvent this problem, we performed transplantation experiments. Neural stem cells were prepared from the spinal cords of 12.5-dpc Sox10 1acZ /Sox10 1acZ embryos and age-matched control littermates, expanded as neurospheres, and injected as singlecell suspensions in equal numbers into the retinas of 3- to 9-day-old $\mathrm{C} 57 \mathrm{BL} / 6 \mathrm{~J}$ recipient mice (Ader et al. 2000). Intraretinal segments of ganglion cell axons are normally unmyelinated, but can be experimentally myelinated by intraretinal transplantation of myelinogenic cells (Laeng et al. 1996; Ader et al. 2000). A fraction of intraretinally grafted stem cells from wild-type donors differentiated into oligodendrocytes in the vicinity of the nerve fiber layer and had produced massive amounts of myelin 1 mo after transplantation. A myelinated nerve fiber layer was visible already by macroscopic inspection of flatmounted retinas in $82 \%$ of host animals (data not shown). Immunostaining of recipient retinas with anti-MAG antibodies confirmed myelination by transplanted cells (Fig. 4a). MAG-immunoreactive axon fascicles were frequently detected in the nerve fiber layer of recipient retinas after sectioning (Fig. 4c). Stem cells from Sox $10^{\text {lacZ }} /$ Sox $10^{\text {lacZ }}$ embryos, on the other hand, failed to myelinate the host nerve fiber layer in a total of 19 transplantations using four independently prepared stem cell cultures, both when analyzed macroscopically or by MAG immunohistochemistry 1 mo or 2 mo after transplantation (Fig. 4b,d). A few residual MAG-positive cells were found in two retinas transplanted with stem cells from Sox $10^{1 a c z} /$ Sox $10^{\text {lacz }}$ embryos, indicating that the block in terminal differentiation is severe but not absolute.

We additionally transplanted stem cells derived from control and Sox $10^{1 a c Z} /$ Sox $10^{\text {lacZ }} \mathrm{em}$ bryos into the severely hypomyelinated brains of mice deficient for MAG and the nonreceptor tyrosine kinase Fyn (Ader et al. 2001). Grafting donor cells from Sox10 lacZ/Sox $10^{\text {lacz }}$ embryos repeatedly produced no or only residual MAG immunoreactivity in MAG/Fyn-deficient host brains 1 mo or 2 mo after transplantation (Fig. 4h; data not shown). Transplantation of stem cells from Sox $10^{\text {lac } Z} /+$ littermates, on the other hand, yielded intense and widespread MAG immunoreactivity in recipient brains, indicative of the presence of numerous donor-derived oligodendrocytes and myelin sheaths (Fig. $4 \mathrm{f}$; data not shown).

We consistently observed a substantial number of $\beta$-galactosidase-positive cells in recipient tissues after transplantation of Sox $10^{\text {lacZ }} /$ Sox $10^{\text {lacZ }}$ donor cells / cf. Fig. 4e,i and Fig. 4g). Given the strong correlation of $\beta$-galactosidase expression and oligodendrocyte fate, it appears likely that injected cells develop into oligodendrocyte progenitors, but fail to terminally differentiate, instead persisting for a significant amount of time after injection as progenitors. The failure of Sox10-deficient neural stem cells to differentiate into myelinating oligodendrocytes in a permissive environment proves that the observed defect is cell-autonomous.

The loss of peripheral glia in Sox10-deficient mice has previously been shown to be largely caused by disruption of erbB3 expression and neuregulin signaling (Britsch et 


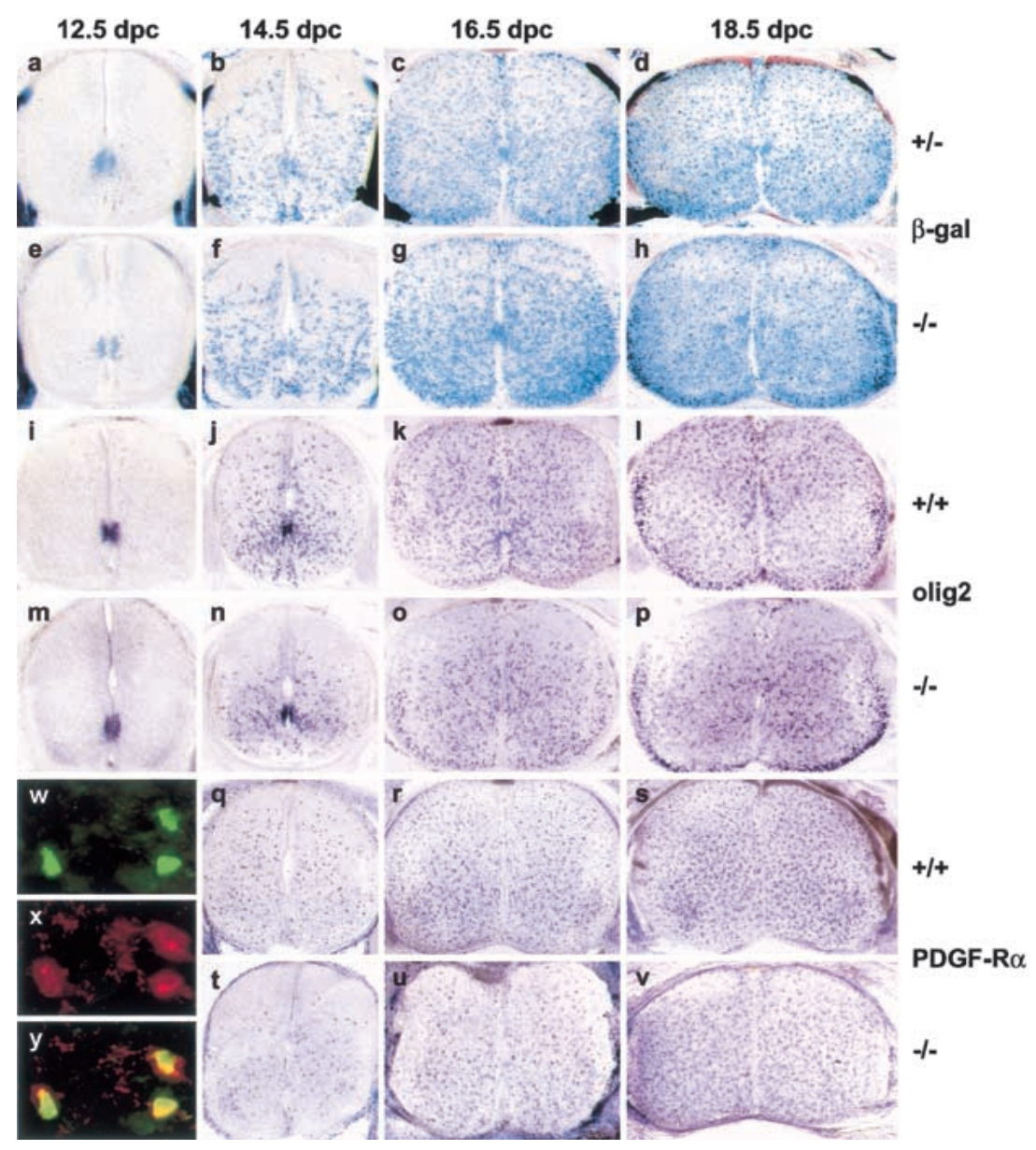

Figure 2. Sox10 expression and development of oligodendrocyte progenitors in the embryonic spinal cord. X-gal staining $(a-h)$ and in situ hybridizations with probes specific for olig2 $(i-p)$ or PDGF receptor $\alpha(q-V)$ were performed on transverse sections from the forelimb region of embryos. $(a-d)$ Sox $10^{1 a c z} /+$ embryos. $(i-1, q-s)$ Wild-type embryos. $(e-h, m-p, t-V)$ Sox10 $1 a c z / S o x 10^{l a c z}$ embryos. $(a, e, i, m) 12.5$ dpc. $(b, f, i, n, q, t)$ $14.5 \mathrm{dpc} .(c, g, k, o, r, u) 16.5 \mathrm{dpc} .(d, h, 1, p, s, v) 18.5 \mathrm{dpc}$. Immunohistochemistry $(w-y)$ on sections of 16.5 -dpc Sox $10^{\text {lac } Z} /+$ embryos with antibodies against $\beta$-galactosidase (green) and PDGF receptor $\alpha$ (red) alone $(w, x)$ and merged $(y)$. Magnification 400x.

al. 2001). Furthermore, erbB3 and erbB2 are up-regulated in oligodendrocytes shortly before terminal differentiation (Canoll et al. 1996), raising the possibility that Sox10 function in the oligodendrocyte lineage is also mediated by erbB3. In this case, homozygous erbB3-deficient and homozygous Sox10-deficient embryos should exhibit a similar oligodendrocyte phenotype. However, myelin gene expression (MBP and PLP) at $18.5 \mathrm{dpc}$ was normal in the absence of erbB3 (Fig. 5a), and retinal transplantation of stem cells from homozygous erbB3deficient embryos yielded normal amounts of myelin (D. Reithmacher, M. Ader, M. Schachner, and U. Bartsch, unpubl.). Additionally, spinal cord expression of erbB3 and erbB2 was comparable in Sox10-deficient and wildtype embryos at $16.5 \mathrm{dpc}$ and $18.5 \mathrm{dpc}$ by various methods (Fig. 5b; data not shown). Taking a recent report into account (Park et al. 2001), both neuregulin receptors and Sox10 therefore appear to be essential for terminal differentiation of oligodendrocytes, however, without the genetic coupling found in peripheral glia.
As evident from the phenotype of the MBP mouse mutant shiverer, loss of myelin gene expression is itself a potential cause for terminal differentiation defects in oligodendrocytes (Chernoff 1981; Roach et al. 1985). In spinal cords of Sox10 lacZ $/$ Sox $10^{\text {lacZ }}$ embryos, in situ hybridization signals were already absent at $14.5 \mathrm{dpc}$ for the early MBP isoforms and the alternatively spliced DM-20 transcript of the PLP gene at the focal origin of oligodendrocyte precursors (Fig. 3 , cf. a,i to e,m). In the absence of Sox10, myelin gene expression is thus already disturbed before the onset of terminal differentiation, which supports the argument that disruption of myelin gene expression could itself be a cause of the terminal differentiation defect.

Using a stable Neuro2A cell line with tetracycline-dependent inducible Sox10 expression (Peirano et al. 2000), we analyzed for Sox10-dependent coinduction of MBP and PLP. As evident from RTPCR analyses, expression of both genes was significantly elevated in this heterologous cell line in the presence of Sox10, whereas expression of the GAPDH control remained unaffected, indicating that at least two major myelin genes are under control of Sox10 (Fig. $5 c)$. There was no up-regulation of MAG under corresponding conditions (data not shown).

In case of the $M B P$ gene, a $3.2-\mathrm{kb}$ fragment from the $5^{\prime}$ flanking region contains all necessary elements to drive expression of a transgene in oligodendrocytes (Foran and Peterson 1992). The same $3.2-\mathrm{kb}$ fragment mediated a 10-fold Sox10-dependent increase in luciferase expression in transient transfections (Fig. 5d). Most of the stimulatory activity was contained within the 256-bp region immediately adjacent to the transcriptional start site. This proximal promoter region is sufficient to drive oligodendrocytespecific transgene expression, albeit with reduced efficiency and intensity (Goujet-Zalc et al. 1993). It contained three binding sites for Sox10. Sites 2 and 3 were bound by single Sox10 molecules and site 1 by two Sox 10 molecules in a cooperative manner (Fig. 5e). As evident from mutagenesis studies, site 1 consists of a high-affinity consensus binding site and a low-affinity nonconsensus element in identical orientation separated by 2 bp (Fig. 5g,h). The low-affinity site was unable to bind Sox10 by itself. Mutation of any one site led to a reduction of the MBP promoter's responsiveness toward Sox10, mutation of all three sites caused an almost complete loss (Fig. 5f). Sox10 thus stimulates MBP expression by directly binding to multiple sites in the proximal promoter region.

Binding behavior and action of Sox10 on the MBP promoter is reminiscent of its function on the promoter of the myelin protein zero $\left(P_{o}\right)$ gene in the PNS (Peirano et al. 2000; Peirano and Wegner 2000). With $P_{O}, M B P$, and 


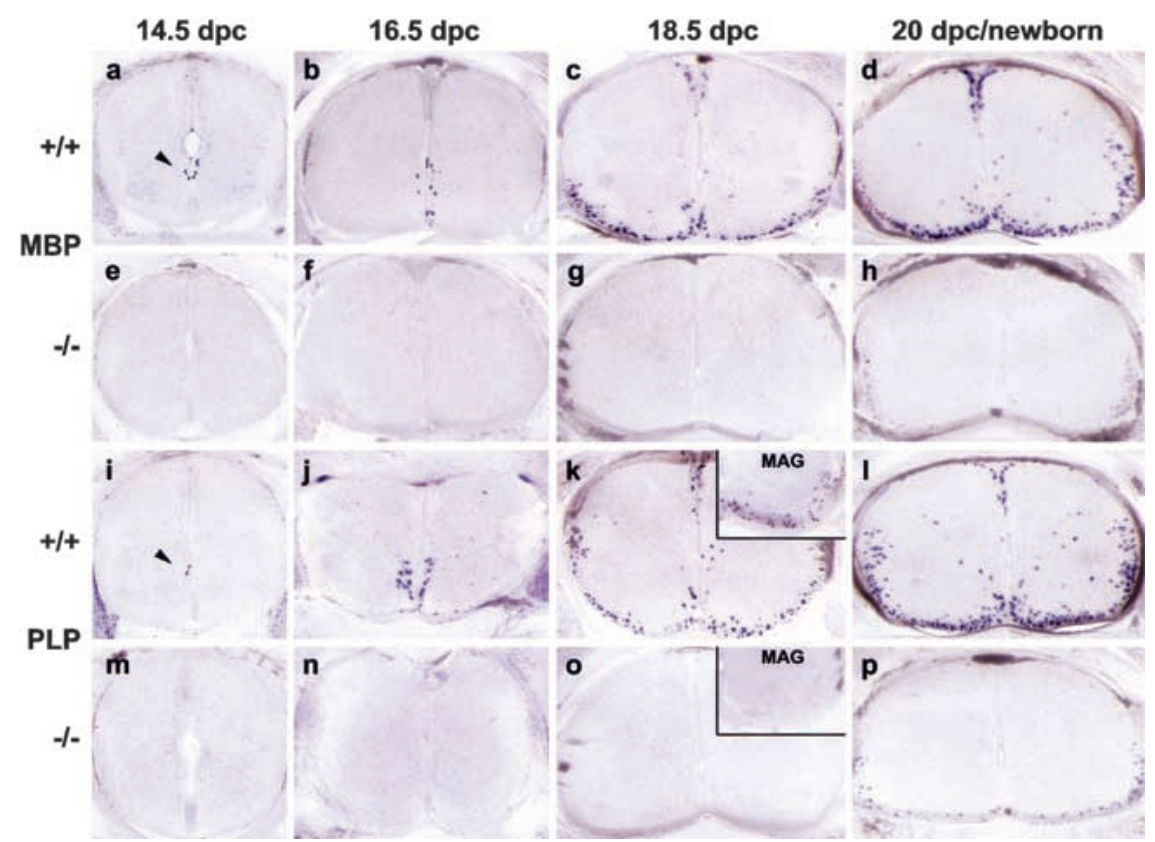

Figure 3. Expression of myelin genes in the embryonic spinal cord in the presence and absence of Sox10. In situ hybridizations with probes specific for MBP $(a-h), \operatorname{PLP}(i-p)$, or MAG $(k, O$, insets) were performed on transverse sections from the forelimb region of embryos. $(a-d, i-1)$ Wild-type embryos. $(e-h, m-p)$ Sox $10^{1 a c Z} /$ Sox $10^{1 a c Z}$ embryos. $(a, e, i, m)$ 14.5 dpc. $(b, f, i, n) 16.5$ dpc. $(c, g, k, o) 18.5$ dpc. $(d, h, l, p)$ Newborn at 20 dpc. The in situ hybridization signal at $14.5 \mathrm{dpc}$ is marked by an arrowhead.

possibly PLP, Sox10 directly controls several myelin genes at the transcriptional level, suggesting that Sox10 is a general regulator of myelin gene expression. Sox proteins depend on cooperating transcription factors for full activity (Wegner 1999; Kamachi et al. 2000). These as yet unidentified cooperation partners may be responsible for
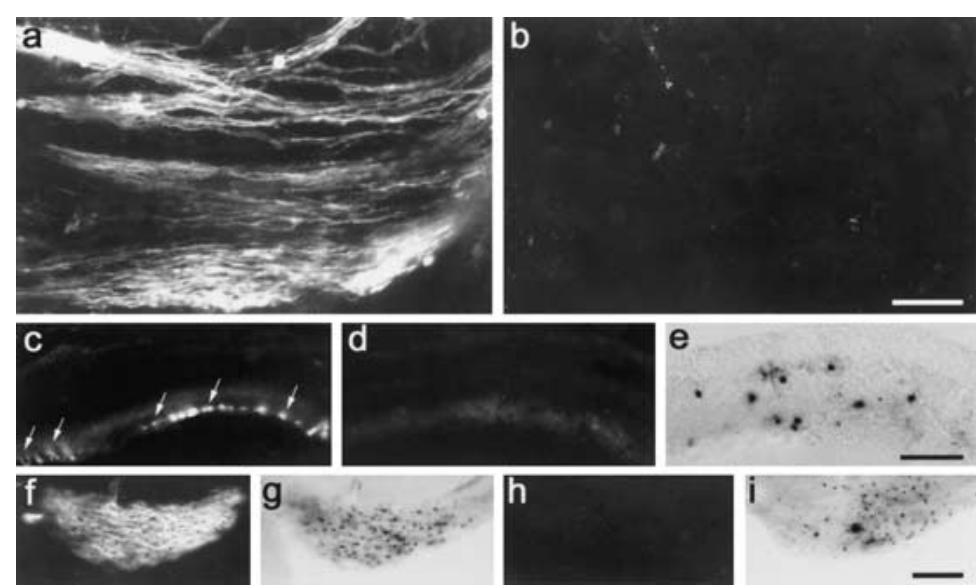

e
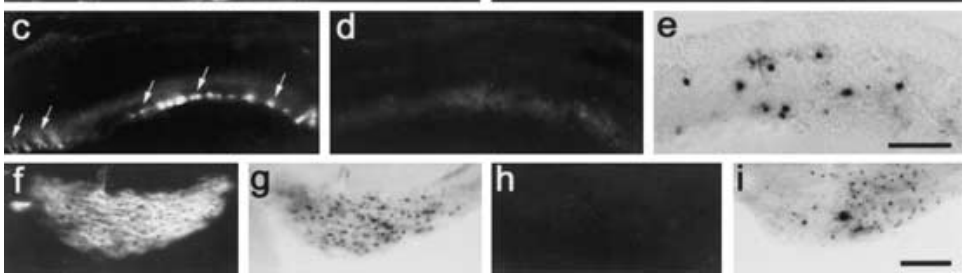

Figure 4. Neural stem cell transplantations. MAG-Immunohistochemistry $(\mathrm{a}-d, f, h)$ and $\mathrm{X}$-gal staining $(e, g, i)$ of wild-type retinas $(a-e)$ and brain sections from MAG/Fyn-deficient mice $(f-i) 1$ mo after transplantation with stem cells derived from 12.5-dpc wild-type $(a, c)$, Sox $10^{1 a c Z} /+(f, g)$, or Sox $10^{\text {lacz }} / \operatorname{Sox} 10^{\text {lacZ }}(b, d, e, h, i)$ embryos. $(a, b)$ Flat-mounted retinas. $(c-e)$ Vibratome-sectioned retinas. $(f-i)$ Corpus callosum. Arrows mark several MAG-immunoreactive axon fascicles in the nerve fiber layer of a recipient retina in $c$. Bars: $b$ (for $a$ and $b$ ), $50 \mu \mathrm{m}$; $e$ (for $c-e$ ), $100 \mu \mathrm{m} ; i($ for $f-i), 200 \mu \mathrm{m}$. the difference in oligodendrocyte versus Schwann cell phenotype. They may also explain the residual myelin gene expression in a small percentage of oligodendrocytes in Sox10-deficient mice.

Sox10 is important in early neural crest cells for development of melanocytes and enteric nervous system (Herbarth et al. 1998; Southard-Smith et al. 1998; Kapur 1999; Britsch et al. 2001). Whereas these early neural crest defects are already visible after loss of a single allele as partial depigmentation and aganglionosis of the colon, additional severe defects in peripheral gliogenesis become only visible in mice in the complete absence of Sox10 function (Britsch et al. 2001). The terminal differentiation failure of oligodendrocytes reported here in homozygous Sox10-deficient mice characterizes a further essential function of Sox10.

Somewhat different from mice, each of the functions of Sox10 is manifested in patients carrying heterozygous Sox10 mutations. Nearly all carriers of heterozygous Sox10 mutations show the typical signs of pigmentation defects and aganglionosis of the colon summarized as Waardenburg-Hirschsprung disease (Pingault et al. 1998; Inoue et al. 1999; Southard-Smith et al. 1999; Touraine et al. 2000; Korsch et al. 2001). Approximately $40 \%$ of all patients additionally exhibit Charcot-Marie-Tooth type-1-like symptoms indicative of peripheral myelinopathies, and a significant $10 \%-20 \%$ fraction suffers from Pelizaeus-Merzbacher disease-like symptoms indicative of central myelinopathies, now explained by the role of Sox10 in oligodendrocyte development (Inoue et al. 1999; Southard-Smith et al. 1999; Touraine et al. 2000; Korsch et al. 2001). In humans, the different rates of phenotypic manifestation in the heterozygous state correlate with the time at which Sox10 becomes essential in the affected cell lineage. Although other possibilities can be envisaged, it is tempting to speculate that early functions are less likely to be compensated by genetic background and environmental cues than late functions.

\section{Materials and methods}

Animal husbandry, genotyping, and transplantations

The Sox10 ${ }^{1 a c Z}$ and erbB3- ${ }^{-}$utations (Riethmacher et al. 1997, Britsch et al. 2001) were kept on a C57BL/6J background. Genotyping was as described (Riethmacher et al. 1997; Britsch et al. 2001). Stem cell cultures from spinal cords of 12.5 -dpc mouse embryos were prepared and expanded as neurospheres in the presence of epidermal growth factor and basic fibroblast growth factor (Ader et al. 2000, 2001). Approximately 50,000 cells of passage 2-4 were transplanted into retinas of 3- to 9-day-old wild-type C57BL/6J as single-cell suspensions. For transplantation into brains of MAG/Fyn-deficient mice, 100,000 cells were injected into the lateral ventricles of neonatal to 1-day-old mice. Mice were killed 1 mo or 2 mo after transplantation, fixed 
a

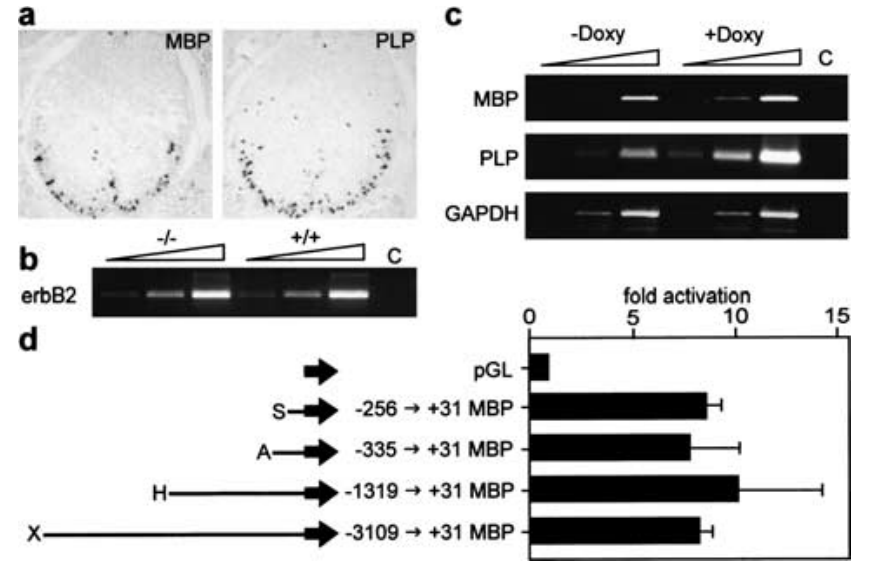

Figure 5. Mechanism of Sox10 function in oligodendrocytes. (a) Expression of the terminal differentiation markers MBP and PLP in spinal cords (forelimb level) of erbB3-deficient embryos at 18.5 dpc as visualized by in situ hybridization. (b) RT-PCR analysis of erbB2 expression in spinal cords of Sox10-deficient (-/-) and wildtype $(+/+)$ embryos at $16.5 \mathrm{dpc}$. (c) RT-PCR analysis on cDNA obtained from Neuro2A Tet-On cells capable of inducibly expressing Sox10. (-Doxy) No doxycycline (Sox10 absent); (+Doxy) doxycycline added (Sox10 present). Transcript levels of MBP, PLP, erbB2, and GAPDH were compared semiquantitatively using increasing numbers of amplification cycles. $(d)$ Sox10-dependent activation of the $M B P$ promoter. Various regions of the $M B P$ promoter were used to drive luciferase reporter gene expression. End points of each fragment are marked by their relative position to the transcriptional start site $(+1)$. Promoter activation is measured as fold induction by comparing luciferase activities in the presence or absence of Sox 10 . (e) Sox binding sites within the MBP promoter. Whole cell extracts with (Sox10) or without (WCE) Sox10 protein were analyzed in electrophoretic mobility shift assays for their ability to bind to radiolabeled oligonucleotides containing the Sox10 binding sites 1-3 from the proximal $M B P$ promoter. $\left(\mathrm{c} / \mathrm{c}^{\prime}\right)$ Sox10-responsive region from the $P_{O}$ promoter binding two Sox10 molecules cooperatively (Peirano et al. 2000). (M) Monomer, (D) dimer. (f) Effect of binding-site mutations on Sox10-dependent activation of the proximal MBP promoter (positions -256 to +31$)$. Mutations that abrogate Sox10 binding to single sites $(\Delta$ Site $1, \Delta$ Site2, $\Delta$ Site 3$)$ or all three sites ( $\triangle$ Site1-3) were introduced into the $M B P$ promoter. Sox10-dependent activation of the resulting $M B P$ promoter mutants was compared to the wild-type version (positions -256 to +31$)$. $(\mathrm{g}$ ) Cooperative binding of Sox10 to site 1 . Both the consensus site (1) and the adjacent non-consensus binding site $\left(1^{\prime}\right)$ were mutated either alone $\left(1 /\right.$ mut and mut $\left./ 1^{\prime}\right)$ or in combination (mut/mut). Sox10 binding to the mutant sites was compared to its binding to the wild-type site $\left(1 / 1^{\prime}\right)$. For sequences see $h$.

by perfusion, and processed for immunohistochemistry and X-gal staining as described below.

In situ hybridization, $X$-gal staining, and immunohistochemistry Embryos were obtained at $11.5-18.5 \mathrm{dpc}$ from staged pregnancies. Paraformaldehyde-fixed, 100 - $\mu \mathrm{m}$-thick vibratome sections or 10- $\mu \mathrm{m}$-thick cryotome sections of genotyped, age-matched mouse embryos, neonatals, or adult mice were used for X-gal staining (Britsch et al. 2001) or in situ hybridization according to standard procedures using DIG-labeled probes for olig2, PDGF receptor $\alpha$, MAG, MBP, and PLP. Immunohistochemistry was carried out on 10- $\mu \mathrm{m}$-thick cryotome sections of adult brain and spinal cord using mouse monoclonal antibodies against $\mathrm{O} 4, \mathrm{MBP}, \mathrm{CN}$ Pase, GFAP (all Roche Biochemicals), MAG (Ader et al. 2000), PDGF receptor $\alpha$ (Pharmingen), and NeuN (Chemicon), in combination with rabbit polyclonal antibodies against lacZ (ICN) as recommended by the manufacturer. Secondary antibodies conjugated to Cy2 and Cy3 immunofluorescent dyes (Dianova) were used for detection.

Tissue culture, transient transfections, RT-PCR, luciferase assays, and gel shifts

Stable Neuro2A cells capable of expressing Sox10 in a tetracycline-inducible manner were kept, treated with doxycycline, and used for RNA preparation as described (Peirano et al. 2000). Detection of products specific for Sox10, PLP, MBP, MAG, erbB2, erbB3, and GAPDH in cDNA generated by reverse transcription of RNA from these cells and embryonic tissue was by semiquantitative PCR. Luciferase reporter plasmids were generated by cloning a 3.2-kb $M B P$ promoter fragment as well as several 5 '-shortened versions (see Fig. $5 \mathrm{~d}$ ) into the pGL2 ${ }_{\text {basic }}$ vector (Promega). Binding sites for Sox 10 in the $M B P$ promoter were inactivated by changing them to GC-rich sequences using site-directed mutagenesis (see Fig. 5h). Transient transfections of these reporters into the inducibly Sox10-expressing Neuro2A cells and luciferase assays were performed as described (Peirano and Wegner 2000). Electrophoretic mobility shift assays followed standard procedures using whole cell extracts containing or devoid of the MIC variant of the Sox10 protein (amino acids 1-180) and ${ }^{32} \mathrm{P}$-labeled oligonucleotide probes containing Sox-binding sites from the $M B P$ promoter in wild-type or mutated version. Sequences of PCR primers and gel shift oligonucleotides are available on request.

\section{Acknowledgments}

We thank C.-H. Heldin, K.A. Nave, A. Roach, and D.H. Rowitch for the gift of plasmids and probes, and B. Schlierf, O. Rosorius, and K. Stolt for help with immunohistochemistry and figures. This study was supported by grant We1326/7-2 from the DFG to M.W.

The publication costs of this article were defrayed in part by payment of page charges. This article must therefore be hereby marked "advertisement" in accordance with 18 USC section 1734 solely to indicate this fact.

\section{References}

Ader, M., Meng, J., Schachner, M., and Bartsch, U. 2000. Formation of myelin after transplantation of neural precursor cells into the retina of young postnatal mice. Glia 30: 301-310.

Ader, M., Schachner, M., and Bartsch, U. 2001. Transplantation of neural precursor cells into the dysmyelinated CNS of mutant mice deficient in the myelin-associated glycoprotein and fyn tyrosine kinase. Eur. J. Neurosci. 14: 561-566.

Britsch, S., Goerich, D.E., Riethmacher, D., Peirano, R.I., Rossner, M., 
Stolt et al.

Nave, K.A., Birchmeier, C., and Wegner, M. 2001. The transcription factor Sox10 is a key regulator of peripheral glial development. Genes \& Dev. 15: 66-78.

Canoll, P.D., Musacchio, J.M., Hardy, R., Reynolds, R., Marchionni, M.A., and Salzer, J.L. 1996. GGF/neuregulin is a neuronal signal that promotes the proliferation and survival and inhibits the differentiation of oligodendrocyte progenitors. Neuron 17: 229-243.

Chernoff, G.F. 1981. Shiverer: An autosomal recessive mutant mouse with myelin deficiency. J. Hered. 72: 128.

Foran, D.R. and Peterson, A.C. 1992. Myelin acquisition in the central nervous system of the mouse revealed by an MBP-Lac Z transgene. $J$. Neurosci. 12: 4890-4897.

Goujet-Zalc, C., Babinet, C., Monge, M., Timsit, S., Cabon, F., Gansmueller, A., Miura, M., Sanchez, M., Pournin, S., Mikoshiba, K. et al. 1993. The proximal region of the MBP gene promoter is sufficient to induce oligodendroglial-specific expression in transgenic mice. Eur. J. Neurosci. 5: 624-632.

Herbarth, B., Pingault, V., Bondurand, N., Kuhlbrodt, K., Hermans-Borgmeyer, I., Puliti, A., Lemort, N., Goossens, M., and Wegner, M. 1998. Mutation of the Sry-related Sox10 gene in Dominant megacolon, a mouse model for human Hirschsprung disease. Proc. Natl. Acad. Sci. 95: 5161-5165.

Inoue, K., Tanabe, Y., and Lupski, J.R. 1999. Myelin deficiencies in both the central and peripheral nervous system associated with a SOX10 mutation. Annals Neurol. 46: 313-318.

Kamachi, Y., Uchikawa, M., and Kondoh, H. 2000. Pairing SOX off: With partners in the regulation of embryonic development. Trends Genet. 16: $182-187$.

Kapur, R.P. 1999. Early death of neural crest cells is responsible for total enteric aganglionosis in Sox10(Dom)/Sox10(Dom) mouse embryos. Pediatr. Dev. Pathol. 2: 559-569.

Korsch, E., Steinkuhle, J., Massin, M., Lyonnet, S., and Touraine, R.L. 2001. Impaired autonomic control of the heart by SOX10 mutation. Eur. J. Pediatr. 160: 68-69.

Kuhlbrodt, K., Herbarth, B., Sock, E., Enderich, J., Hermans-Borgmeyer, I., and Wegner, M. 1998a. Cooperative function of POU proteins and Sox proteins in glial cells. J. Biol. Chem. 273: 16050-16057.

Kuhlbrodt, K., Herbarth, B., Sock, E., Hermans-Borgmeyer, I., and Wegner, M. 1998b. Sox10, a novel transcriptional modulator in glial cells. J. Neurosci. 18: 237-250.

Laeng, P., Molthagen, M., Yu, E.G., and Bartsch, U. 1996. Transplantation of oligodendrocyte progenitor cells into the rat retina: Extensive myelination of retinal ganglion cell axons. Glia 18: 200-210.

Lu, Q.R., Yuk, D., Alberta, J.A., Zhu, Z., Pawlitzky, I., Chan, J., McMahon, A.P., Stiles, C.D., and Rowitch, D.H. 2000. Sonic hedgehogregulated oligodendrocyte lineage genes encoding bHLH proteins in the mammalian central nervous system. Neuron 25: 317-329.

Park, S.-K., Miller, R., Krane, I., and Vartanian, T. 2001. The erbB2 gene is required for the development of terminally differentiated spinal cord oligodendrocytes. J. Cell. Biol. 154: 1245-1258.

Peirano, R.I. and Wegner, M. 2000. The glial transcription factor Sox10 binds to DNA both as monomer and dimer with different functional consequences. Nucleic Acids Res. 28: 3047-3055.

Peirano, R.I., Goerich, D.E., Riethmacher, D., and Wegner, M. 2000. Protein zero expression is regulated by the glial transcription factor Sox10. Mol. Cell. Biol. 20: 3198-3209.

Pingault, V., Bondurand, N., Kuhlbrodt, K., Goerich, D.E., Prehu, M.-O., Puliti, A., Herbarth, B., Hermans-Borgmeyer, I., Legius, E., Matthijs, G., et al. 1998. Sox10 mutations in patients with Waardenburg-Hirschsprung disease. Nature Genet. 18: 171-173.

Riethmacher, D., Sonnenberg-Riethmacher, E., Brinkmann, V., Yamaai, T., Lewin, G.R., and Birchmeier, C. 1997. Severe neuropathies in mice with targeted mutations in the ErbB3 receptor. Nature 389: 725-730.

Roach, A., Takahashi, N., Pravtcheva, D., Ruddle, F., and Hood, L. 1985 Chromosomal mapping of mouse myelin basic protein gene and structure and transcription of the partially deleted gene in shiverer mutant mice. Cell 42: 149-155.

Southard-Smith, E.M., Kos, L., and Pavan, W.J. 1998. Sox10 mutation disrupts neural crest development in Dom Hirschsprung mouse model. Nat. Genet. 18: 60-64.

Southard-Smith, E.M., Angrist, M., Ellison, J.S., Agarwala, R., Baxevanis, A.D., Chakravarti, A., and Pavan, W.J. 1999. The Sox10(Dom) mouse:
Modeling the genetic variation of Waardenburg-Shah (WS4) syndrome. Genome Res. 9: 215-225.

Touraine, R.L., Attie-Bitach, T., Manceau, E., Korsch, E., Sarda, P., Pingault, V., Encha-Razavi, F., Pelet, A., Auge, J., Nivelon-Chevallier, A., et al. 2000. Neurological phenotype in Waardenburg syndrome type 4 correlates with novel SOX10 truncating mutations and expression in developing brain. Am. J. Hum. Genet. 66: 1496-1503.

Wegner, M. 1999. From head to toes: The multiple facets of Sox proteins. Nucleic Acids Res. 27: 1409-1420.

Woodruff, R.H., Tekki-Kessaris, N., Stiles, C.D., Rowitch, D.H., and Richardson, W.D. 2001. Oligodendrocyte development in the spinal cord and telencephalon: Common themes and new perspectives. Int. J. Dev. Neurosci. 19: 379-385.

Xu, X., Cai, J., Fu, H., Wu, R., Qi, Y., Modderman, G., Liu, R., and Qiu, M. 2000. Selective expression of Nkx-2.2 transcription factor in chicken oligodendrocyte progenitors and implications for the embryonic origin of oligodendrocytes. Mol. Cell. Neurosci. 16: 740-753.

Zhou, Q., Wang, S., and Anderson, D.J. 2000. Identification of a novel family of oligodendrocyte lineage-specific basic helix-loop-helix transcription factors. Neuron 25: 331-343. 


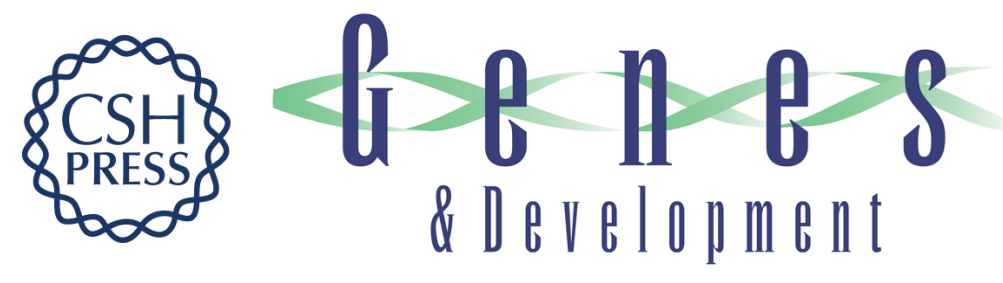

\section{Terminal differentiation of myelin-forming oligodendrocytes depends on the transcription factor Sox10}

C. Claus Stolt, Stephan Rehberg, Marius Ader, et al.

Genes Dev. 2002, 16:

Access the most recent version at doi:10.1101/gad.215802

References This article cites 29 articles, 8 of which can be accessed free at: http://genesdev.cshlp.org/content/16/2/165.full.htmI\#ref-list-1

License

Email Alerting

Receive free email alerts when new articles cite this article - sign up in the box at the top Service right corner of the article or click here.

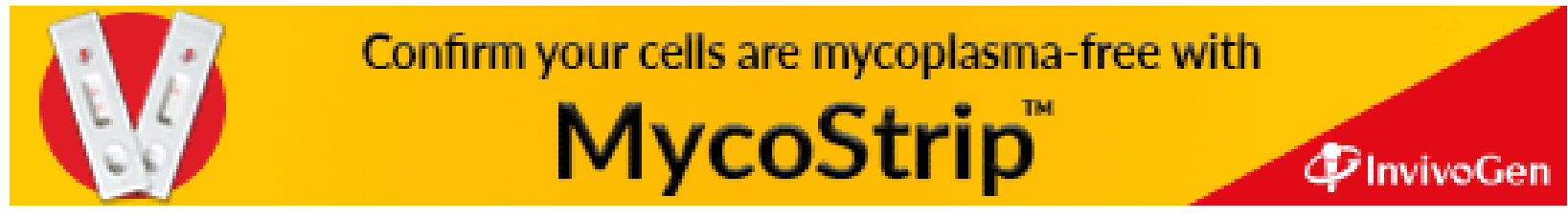

